\title{
Plant defense-related enzymes against pathogens: A Review
}

\author{
K. Prasannath \\ Department of Agricultural Biology, Faculty of Agriculture, Eastern University Sri Lanka, \\ Chenkalady
}

\begin{abstract}
Plant disease control is mainly based on the use of fungicides, bactericides, and insecticides-chemical compounds toxic to plant invaders, causative agents, or vectors of plant diseases. However, the detrimental effect of these chemicals or their degradation products on the environment and human health strongly imposes the search for novel, harmless means of disease control. Therefore, it is essential to introduce environmentally-friendly alternative measures for management of plant diseases. Induced plant resistance is one of the promising non-chemical strategies for the effective management of diseases. The host plant mediated resistance is governed by defense response genes encoding for production of various pathogenesis-related (PR) proteins. This review chiefly explains the biochemical response of plant defense mechanism pertaining to defense-related enzymes which have been identified as PR proteins.
\end{abstract}

Keywords: Defense-related enzymes, Induced plant resistance, Pathogenesis-related proteins

\section{Introduction}

In nature, plants are attacked by a diverse range of biotic agents including pathogens and herbivorous insects which can have devastating effects on host plants (Ebrahim et al., 2011). Application of pesticides has been the chief method of controlling plant diseases (Prasannath et al., 2014). However, there is a growing concern in developing alternative measures aiming to minimize the harmful impacts of pesticides on the environment and human health. Inducing systemic resistance against plant pathogens is one such environmentally-friendly approach of disease management (Prasannath and De Costa, 2015).

When plants are attacked by pathogens and herbivores, these stresses can induce biochemical and physiological changes in plants, such as physical strengthening of the cell wall through lignification, suberization, and callose deposition; by producing phenolic compounds, phytoalexins and pathogenesis-related (PR) proteins which subsequently prevent various pathogen invasion (Bowles, 1990). Among these, production and accumulation of PR proteins in plants in response to invading pathogen is very important. Plants enhance defense responses by inducing activity of a broad spectrum of defense enzymes which are PR proteins, namely peroxidase, $\beta-1,3-$ glucanase, chitinase, polyphenol oxidase and phenylalanine ammonia lyase which can slow an herbivore's feeding and also the rate of disease spread (Deborah et al., 2001; Kumari and Vengadaramana, 2017).

Host plant mediated resistance against pathogens

Interactions between plants and pathogens can lead in to successful infection (compatible response) or resistance (incompatible response). In incompatible relations, viruses, bacteria or

Received 17 April 2017. Accepted 10 July 2017. Corresponding author: prasannathk@esn.ac.lk 
fungi which infect plants will elicit a set of localized responses in and around the infected host cells. These responses consist with an oxidative burst (Lamb and Dixon, 1997), which can lead to cell death (Kombrink and Schmelzer, 2001). The pathogen may be 'trapped' in dead cells. It can lead to prevent the spreading from the site of primary infection. There are local responses in the surrounding cells which inhibit the penetration of pathogens by changing cell wall composition and synthesis of antimicrobial compounds such as PR proteins and phytoalexins (Kuc, 1995; Hammerschmidt, 1999). Also plants respond to attacks by pathogens through various defense responses. The accumulations of several factors like defense-related enzymes and inhibitors which lead to prevent infection of pathogens are several defense responses. The enzyme activities and total phenol content were increased significantly in resistant cultivars upon pathogen inoculation (Vanitha et al., 2009).

Plants possess a range of active defense mechanisms which respond to biotic stresses. Diseases can be reduced due to trigger of defense mechanisms in plants by a stimulus, prior to infection by a plant pathogen. Systemic acquired resistance (SAR) and induced systemic resistance (ISR) are two forms of induced resistance in plant. Combination of ISR and SAR can increase defense against pathogens that are resisted through both pathways than ISR and SAR alone (Choudhary, 2007).

\section{Induced Systemic Resistance (ISR)}

When an antagonist is present at the site of exposure, an antimicrobial substance could be synthesized by the biological control agent and transported through the plant, inhibiting the pathogen directly. The induced resistance does not necessarily need to be systemic, but a local protection can be formed as a result of the induced resistance. ISR is induced by plant growth promoting rhizobacteria which are believed to produce a translocatable signal that induces protection in tissues far from the roots where the antagonist was delivered. A systemic response of the plant to an elicitor shows that induced resistance is taking place (van Loon et al., 1998). ISR is independent of salicylic acid, but it is mediated by jasmonic acid and/or ethylene, which are produced following applications of some nonpathogenic rhizobacteria (He et al., 2004). ISR is accompanied by the expression of a set of genes distinct from the PR protein genes (Pieterse et al., 1998).

\section{Systemically Acquired Resistance (SAR)}

Plants can acquire resistance against the initiating of diseases through various biological agents including necrotizing pathogens, non-pathogens and soil borne rhizosphere bacteria and fungi. SAR is a mechanism of induced defense responses (Gajanayaka et al., 2014). In SAR a mobile signal is generated in the site of induction and translocated in the plant, bringing about an induced state in tissues, far from the site of exposure to the elicitor (van Loon et al., 1998). It provides long-lasting protection against a broad spectrum of microorganisms. SAR requires the signal molecule salicylic acid and it is associated with accumulation of PR proteins, which are believed to contribute to resistance (He et al., 2004). The development of SAR is associated with various cellular defense responses, such as synthesis of PR proteins and phytoalexins, rapid changes in cell wall, and enhanced activity of various defense-related enzymes (Durrant and Dong, 2004). SAR is induced systemically after inoculation with necrotizing pathogens or application of some chemicals such as salicylic acid (Pieterse et al., 1998; Prasannath et al., 2014). Certain plant growth promoting microorganisms could stimulate defense activity and enhance plant resistance against soil borne pathogens (Whipps et al., 2001). 


\section{Pathogenesis-related (PR) proteins}

PR proteins are a structurally diverse group of plant proteins that are considered to play important roles in plant disease resistance (Mahendranathan et al., 2016). They are widely distributed in plants in trace amounts, but are produced in much greater concentration following pathogen attack or stress. PR proteins exist in plant cells intracellularly and also in the intercellular spaces, particularly in the cell walls of different tissues (Agrios, 2005). The several groups of PR proteins have been classified according to their function, serological relationship, amino acid sequence, molecular weight, and some other properties. Currently PR proteins are categorized into 17 families according to their properties and functions, including $\beta$-1,3-glucanases, chitinases, thaumatin-like proteins, peroxidases, ribosome-inactivating proteins, defensins, thionins, nonspecific lipid transfer proteins, oxalate oxidase, and oxalate-oxidase-like proteins (van Loon and van Strien, 1999). PR proteins are either extremely acidic or extremely basic and therefore are highly soluble and reactive (Legrand et al., 1987). The signal compounds responsible for induction of PR proteins include salicylic acid, ethylene, xylanase, polypeptide systemin, jasmonic acid and probably others (Agrios, 2005).

\section{Defense-related enzymes}

Defense enzymes such as peroxidase, polyphenol oxidase, phenylalanine ammonia lyase, chitinase and $\beta-1,3-$ glucanase are related to resistance inducement in plants (Prasannath and De Costa, 2015; Gajanayaka et al., 2014; Seneviratne et al., 2014). Peroxidases have been implicated in a range of defenserelated processes, including the hypersensitive response, lignification, cross-linking of phenolics and glycoproteins, suberization and phytoalexin production (Nicholson \& Hammerschmidt, 1992; Wojtaszek, 1997). Polyphenol oxidase catalyzes the phenolic compounds to quinones, thus decreasing of nutritional quality of food and reducing protein digestibility (Felton and Duffey, 1990; Felton et al., 1994). The intensification of production of phenolic compounds, known as defense molecules of plants against pathogens and insects, is indicated by an increase in phenylalanine ammonia lyase activity in wounded plant tissues (Bi and Felton, 1995). Chitinase and $\beta$-1,3-glucanase are responsible for the hydrolysis of cell wall components in sequence such as chitin and $\beta$-1,3-glucans (Ebrahim et al., 2011).

\section{Peroxidases}

Peroxidases are a distinguished class of PR proteins and induced in host plant tissues by pathogen infection. They belong to PR protein 9 subfamily and are expressed to limit cellular spreading of infection through establishment of structural barriers or generation of highly toxic environments by massively producing reactive oxygen species (Passardi et al., 2005). Peroxidase activity or peroxidase gene expression in higher plants is, indeed, induced by fungi (Sasaki et al., 2004), bacteria (Lavania et al., 2006), viruses (Diaz-Vivancos et al., 2006), and viroids (Vera et al., 1993). Cross-linking of the phenolic monomers in oxidative coupling of lignin subunits has been associated with peroxidase using $\mathrm{H}_{2} \mathrm{O}_{2}$ as oxidant. One significant event in plant defense reactions is oxidative burst, a general early response of host plant cells to pathogen infection and elicitor treatment (Almagro et al., 2009). Peroxidase also participates in the production of ethylene the concentration of which increases frequently in pathogenesis process (Tudzynski, 1997).

Peroxidase is a key enzyme in the biosynthesis of lignin and suberin. Peroxidases have been associated with a 
number of physiological functions that may contribute to resistance, through hypersensitive responses, oxidation of hydroxyl cinnamyl alcohol into free radical intermediates, phenol oxidation, polysaccharide cross linking, cross linking of extension monomers, and the deposition of phenolic material in plant cell walls during resistance reactions (Thakker et al., 2013). When peroxidase level increases due to the induced systemic resistance (Prasannath et al., 2014), quick synthesis of reactive oxygen derivatives by oxidative burst leads to cell death and inhibits pathogenic activities (Halfeld-Vieira et al., 2006). Peroxidase oxidizes phenolics to quinines and generates hydrogen peroxide. It is antimicrobial and also releases highly reactive free radicals and further increases the rate of polymerization of phenolic compounds into lignin-like substances. These substances are then deposited in cell walls and papillae and hinder the further growth and development of the pathogen (Agrios, 2005).

\section{$\beta$-1,3-glucanases}

They have been classified as PR-2 proteins which are $\beta$-glucanases (glucan endo-1,3$\beta$-glucosidases) able to catalyze endo-type hydrolytic cleavage of the $1,3-\beta-\mathrm{D}$ glucosidic linkages in $\beta$-1,3-glucans. $\beta-1,3-$ Glucans are the major components of the cell walls of oomycetes, a group of fungi that do not contain chitin (Wessels et al., 1981). The induction of $\beta$-glucanase as part of the hypersensitive reaction is a stereotypic response; the pattern of induction is similar for viral, bacterial, and fungal pathogens. It creates resistance against various fungi such as Aspergillus parasiticus, A. flavs, Blumeria graminis, Colletotrichum lagenarium, Fusarium culmorum, Fusarium oxysporum, fusarium udum, Macrophomina phaseolina and Treptomyces sioyaensis (Rezzonico, 1998; Wu and Bradford, 2003; Hong and Meng, 2004; Wrobel-Kwiatkowska et al., 2004, Liang et al., 2005; Roy-Barman et al., 2006). $\beta$-glucanases participate in the decomposition of glucans like callose which occurs in plant tissues as one of the components of wall modifications involved in resistance responses (Smart, 1991). Even though antifungal $\beta$-glucanase I appear to be tailored for defense against fungi, other studies of $\beta$-glucanase Ideficient mutants generated by antisense transformation suggest that these enzymes also play a vital role in viral pathogenesis (Beffa et al., 1996). The endotype $\beta$-1,3-glucanase enzyme seems to be most important for the degradation of the callosic walls, while the exotype $\beta-1,3-$ glucanase is involved in the further hydrolysis of released oligosaccharides. It has been proposed that these glucanohydrolases perform in at least two different ways: directly, by degrading the cell walls of the pathogen and indirectly, by promoting the release of cell wallderived materials that can act as elicitors of defense reactions (Bowles et al., 1990).

\section{Chitinases}

Chitinases are large and diverse group of enzymes and also one of the important plant pathogenesis related (PR) protein that degrades chitin, it improves plant defence against chitin containing plant pathogens (Jalil et al., 2015). $\beta$-1,3-glucan and chitin, polymer of $\mathrm{N}$ acetylglucosamine are major cell wall components of many fungi. Since $\beta-1,3-$ glucanase and chitinases have been shown to be capable of attacking cell wall of fungal pathogens, these enzymes have been proposed as direct defense enzymes of plants (Abeles et al., 1970). In addition, Mauch et al. (1988) reported that in combination, chitinase and $\beta$-1,3glucanase act synergistically to inhibit fungal growth. The mode of action of chitinase is relatively simple. They degrade the cell wall chitin polymers in situ, resulting in a weakened cell wall and rendering fungal cells osmotically sensitive (Jach et al., 1995). These 
chitinases have significant antifungal activities against plant pathogenic fungi like Alternaria spp. for rice grain discoloration, Rhizoctonia solani for rice sheath blight, Bipolaris oryzae for rice brown spot, Botrytis cinerea for tobacco blight, Curvularia lunata for clover leaf spot, Fusarium oxysporum, F. udum, Mycosphaerella arachidicola and Pestalotia theae for tea leaf spot (Chu and Ng, 2005; Saikia et al., 2005; Kirubakaran and Sakthivel, 2006). The level of protection observed in the plants is variable and may be influenced by the specific activity of the enzyme, its localization and concentration within the cell, the characteristics of the fungal pathogen, and the nature of the host-pathogen interaction (Punja and Zhang, 1993).

\section{Phenylalanine ammonia lyase (PAL)}

PAL is the key enzyme that is responsible for linking primary metabolism of aromatic amino acids with secondary metabolic products (MacDonald and Dcunha, 2007). PAL catalyzes the nonoxidative deamination of phenylalanine in to trans-cinnamic acid and ammonia which is the initial step in the biosynthesis of phenolic compounds. PAL is a reliable treatment for the genetic condition phenylketonuria, due to the natural ability of the enzyme to breakdown Lphenylalanine (MacDonald and Dcunha, 2007). PAL is one of the most extensively studied enzymes in plants due to synthesis of various phenolic compounds as well as anthocyanin which are responsible for the resistance of plant pathogens (Dixon and Paiva, 1995). Changes in PAL activity can take place during pathological events (Seneviratne $e t$ al., 2014). PAL activity can be induced by the plant hormone ethylene and plant signal molecules including salicylic acid and jasmonic acid (Campos-Vargas and Saltveit, 2002; Kim et al., 2007), and also it can be induced by various biotic and abiotic stresses such as pathogen invasion, wounding, chilling and ozone (Lafuente et al., 2003). When treated strawberry plants with abscisic acid, anthocyanin and PAL activity are increased (Jiang and Joyce, 2003). All phenylpropanoids compounds are derived from cinnamic acid, which is formed from phenylalanine by the activity of PAL. These phenylpropanoids are accountable for disease resistance, crop development and mechanical support (Barber and Mitchell, 1997; Chen et al., 2007; Harakava, 2005) as well as insect pest damages (War et al., 2012). PAL activity may be regulated by feedback inhibition by the pathway product, cinnamic acid, which may modify the expression of the PAL gene (Christensen et al., 2001; Del Rio et al., 2004).

\section{Polyphenol oxidase (PPO)}

PPOs are a group of copper containing enzymes that catalyze oxidation of hydroxy phenols to their quinone derivatives, which have antimicrobial activity (Chunhua et al., 2001). Because of its reaction products and wound inducibility, PPO plays a role in defense against plant pathogens (Mayer and Harel, 1979). Plants immediately respond to pathogens so there is an immediate rise in PPO indicating immediate synthesis of antimicrobials to ward off the pathogens. Pathogen-induced PPO activity continues to be reported for various plant taxa, including monocots and dicots (Chen et al., 2000; Deborah et al., 2001). Increase of PPO activity was reported in banana roots treated with Fusarium oxysporum derived elicitor by Thakker et al. (2007). A striking increase of PPO activity was observed in banana roots treated with Psuedomonas fluorescens against fusarium wilt (Sarvanan et al., 2004). Similarly, studies showing correlations of high PPO levels in cultivars or lines with high pathogen resistance continue to provide support for a pathogen defense role of PPO (Raj et al., 2006). Several groups have also attempted to correlate the protective effects of rhizosphere bacteria with an induction of defense enzymes including PPO, with 
mixed success (Chen et al., 2000; Ramamoorthy et al., 2002).

$\mathrm{Li}$ and Steffens (2002) suggested several possibilities, including general toxicity of PPO-generated quinones to pathogens and plant cells, accelerating cell death, alkylation and reduced bioavailability of cellular proteins to the pathogen, crosslinking of quinones with protein or other phenolics, forming a physical barrier to pathogens in the cell wall, and quinone redox cycling leading to $\mathrm{H}_{2} \mathrm{O}_{2}$ and other reactive oxygen species (Jiang and Miles, 1993). While reactive oxygen species are known to be important factors in plant pathogen interactions and defense signaling, PPO is implicated in the formation of melanin-like polymers in potato black spot lesions (Stevens et al., 1998). However, none of these hypotheses of how PPO might affect pathogens has been tested rigorously so far.

\section{Conclusion}

Plants protect themselves against biotic factors by physical strengthening of the cell wall through lignification, suberization, and producing various PR proteins including defense-related enzymes such as peroxidase, $\beta-1,3$ glucanase, chitinase, phenylalanine ammonia lyase and polyphenol oxidase in response to pathogen infection. These defense enzymes are also induced in plants through application of exogenous substances so that more studies are needed to investigate the defense responses that are triggered by these elicitor treatments. Thus, the knowledge on plant defense-related enzymes can definitely be beneficial for the development of new control strategies.

\section{References}

Abeles, F.B., Bosshart, P., Forrence, L.E. and Habiz, W. (1970). Preparation and purification of glucanase and chitinase from bean leaves. Plant Physiology. 47(1): 129-134.

Agrios, G.N. (2005). Chapter 6 - How plants defend themselves against pathogens. In: Plant Pathology. 5th Ed., Academic Press. 232.

Almagro, L., Gomez Ros, L.V., BelchiNavarro, S., Bru, R., Ros Barcelo, A. and Pedreno, M.A. (2009). Class III peroxidases in plant defence reactions. Journal of Experimental Botany. 60(2): 377390.

Barber, M.S. and Michell, H.J. (1997). Regulation of Phenylalpropanoid metabolism in relation to lignin biosynthesis in plants. Int.Rev.cytol. 172: 243-293.

Beffa, R.S., Hofer, R.M., Thomas, M. and Meins, F. (1996). Decreased susceptibility to virus disease of $\beta$-1,3-glucanasedeficient plants generated by antisense transformation. Plant Cell. 8: 1001-1011.

Bi, J.L. and Felton, G.W. (1995). Foliar oxidative and insect herbivory: primary compounds, secondary metabolites, and reactive oxygen species as components of induced resistance. Journal of Chemical Ecology. 21: 1511-1530.

Bowles, D.J. (1990). Defense-related proteins in higher plants. Ann. Rev. Biochem. 59: 873-907.

Campos-Vargas, R. and Saltveit, M.E. (2002). Involvement of putative chemical wound signals in the induction of phenolic metabolism in wounded lettuce. Physiol. Plant. 114: 73-84.

Chen, A.H., Chai, Y.R., Li, J.N. and Chen, L. (2007). Molecular cloning of two genes encoding cinnamate 4-hydroxylase $(\mathrm{C} 4 \mathrm{H})$ from oilseed rape (Brassica napus). J. Biochem. Mol. Biol. 40: 247-260. 
Chen, C., Belanger, R., Benhamou, N. and Paulitz, T.C. (2000). Defense enzymes induced in cucumber roots by treatment with plant growth-promoting rhizobacteria (PGPR) and Pythium aphanidermatum. Physiol Mol Plant Pathol. 56: 13-23.

Choudhary, D.K., Prakash, A. and Johri, B.N. (2007). Induced systemic resistance (ISR) in plants: mechanism of action. Indian J. Microbiology. (47): 289-297.

Christensen, J.H., Overney, S., Rohde, A., Diaz, W.A., Bauw, J., Simon, P., Van Montagu, M. and Boerjan, W. (2001). The syringaldazine-oxidizing peroxidase PXP 3-4 from poplar xylem: cDNA isolation, characterization and expression. Plant $\mathrm{Mol}$ Biol. 47: 581-593.

Chu, K.T. and Ng, T.B. (2005). Purification and Characterization of a Chitinase-Like Antifungal Protein from Black Turtle Bean With Stimulatory Effect on Nitric Oxide Production by Macrophages. Biol. chem. 386: 19-24.

Chunhua, S., Ya, D., Bingle, X., Xiao, L., Yonshu, X. and Qinguang, L. (2001). The purification and spectral properties of PPO I from Nicotianan tababcum. Plant Molecular Biology. 19: 301-314.

Deborah, S.D., Palaniswami, A., Vidhyasekaran, P. and Velazhahan, R. (2001). Time-course study of the induction of defense enzymes, phenolics and lignin in rice in response to infection by pathogen and non-pathogen. J Plant Dis Prot. 108: 204-216.

Del Rio, J.C., Gutiérrez, A., Hernando, M., Landín, P., Romero, J. and Martínez, A.T. (2004). Correlation between lignin syringyl/guaiacyl ratio in eucalypt wood and paper pulp yield. Proceedings of the $16^{\text {th }}$ International Symposium on Analytical and Applied Pyrolysis. Alicante, Spain.
Diaz-Vivancos, P., Rubio, M. and Mesonero, V. (2006). The apoplastic antioxidant system in Prunus: response to long-term plum pox virus infection. Journal of Experimental Botany. 57(14): 3813-3824.

Dixon, R.A., Paiva, N.L. and Bhattacharyya, M.K. (1995). Engineering disease resistance in plants: An overview. In: Molecular Methods in Plant Pathology, R.P. Singh and U.S. Singh (eds). CRC Press, Boca Raton. pp. 249-270.

Durrant, W.E. and Dong, X. (2004). Systemic acquired resistance. Annu Rev Phytopathol. 42: 185-209.

Ebrahim, S. and Usha, K. and Singh, B. (2011). Pathogenesis Related (PR) Proteins in Plant Defense Mechanism. In: Science against microbial pathogens: communicating current research and technological advances, A. Mendez-Vilas (ed). pp. 1043-1054.

Felton, G.W. and Duffey, S.S. (1990). Inactivation of baculovirus by quinones formed in insect-damaged plant tissues. Journal of Chemical Ecology. 16: 1221-1236.

Felton, G.W., Summers, C.B. and Mueller, A.J. (1994). Oxidative responses in soybean foliage to herbivory by bean leaf beetle and three-cornered alfalfa hopper. Journal of Chemical Ecology. 20: 639-650.

Gajanayaka, G. M. D. R., Prasannath, K. and De Costa, D. M. (2014). Variation of chitinase and $\beta-1,3$-glucanase activities in tomato and chilli tissues grown under different crop management practices and agroecological regions. Proceedings of the Peradeniya University International Research Sessions. $4^{\text {th }}-5^{\text {th }}$ July 2014. 18: 519.

Halfeld-Vieira, B.A., Vieira Jr., J.R., Romeiro, R.S., Silva, H.S.A. and BaracatPereira, M.C. (2006). Introduction of systemic resistance in tomato by the autochthonous phylloplane resident 
Bacillus cereus. Pesq. Agropec. Bras. 41(8): 1247-1252.

Hammerschmidt, R. (1999). Induced disease resistance: how do induce plants stop pathogens. Physiological and Molecular Plant Pathology. 55: 77-84.

Harakava, R. (2005). Genes encoding enzymes of the lignin biosynthesis pathway in Eucalyptus. Genet. Mol. Biol. 28: 601-607.

He, P., Chintamanani, S., Chen, Z., Zhu, L., Kunkel, B.N., Alfano, J.R., Tang, X. and Zhou, J.M. (2004). Activation of a COI1dependentpathway in Arabidopsis by Pseudomonas syringae type III effectors and coronatine. Plant J. 37:589-602

Hong, T.Y. and Meng, M. (2004). Biochemical Characterization and Antifungal Activity of an endo-1,3-13Glucanase of Paenibacillus sp. Isolated from Garden Soil. Appl. Microbiol. Biotechnol. 61(5-6): 472-478.

Jach, G., Gornhardt, B., Mundy, J., Logemann, J., Pinsdorf, E., Leah, R., Schell, J. and Maas, C. (1995). Enhanced Quantitative Resistance against Fungal Disease by Combinatorial Expression of Different Barley Antifungal Proteins in Transgenic Tobacco. Plant J. 8: 97-109.

Jalil, S.U. Mishra, M. and Ansari, M.I. (2015). Current View on Chitinase for Plant Defence. Trends in Biosciences. 8(24): 6733-6743.

Jiang, Y. and Miles, P.W. (1993). Generation of $\mathrm{H}_{2} \mathrm{O}_{2}$ during enzymatic oxidation of catechin. Phytochemistry. 33: 29-34.

Jiang, Y.M. and Joyce, D.C. (2003). ABA effects on ethylene production, PAL activity, anthocyanin and phenolic contents of strawberry fruit. Plant Growth Regul. 39: 171-174.
Kim, H.J., Fonseca, J.M., Choi, J.H. and Kubota, C. (2007). Effect on methyl jasmonate on phenolic compounds and carotenoids of Romaine Lettuce (Lactuca sativa L.). J. Agri. Food Chem. 55: 1036610372.

Kirubakaran, S.I. and Sakthivel, N. (2006). Cloning and Overexpression of Antifungal Barley Chitinase Gene in Escherichia coli. Pro. Express. Purific. 52(1): 159-166.

Kombrink, E. and Schmelzer, E. (2001). The hypersensitive response and its role in local and systemic disease resistance. European Journal of Plant Pathology. 107: 69-78.

Kuc, J. (1995). Phytoalexins, stress metabolism, and disease resistance in plants. Annual Review of Phytopathology. 33: 275-297.

Kumari, Y.S.M.A.I. and Vengadaramana, A. (2017). Stimulation of Defense Enzymes in Tomato (Solanum lycopersicum L.) and Chilli (Capsicum annuum L.) in Response to Exogenous Application of Different Chemical Elicitors. Universal Journal of Plant Science. 5(1): 10-15.

Lafuente, M.T., Zacarias, L., MartinezTelez, M.A., Sanchez-Ballesta, M.T. and Granell, A. (2003). Phenylalanine ammonia-lyase and ethylene in relation to chilling injury as affected by fruit age in citrus. Postharvest Biol. Technol. 29: 308-317.

Lamb, C. and Dixon, R.A. (1997). The Oxidative burst in plant disease resistance. Annual Review of Plant Physiology and Plant Molecular Biology. 48: 251-275.

Lavania, M., Chauhan, P.S., Chauhan, S.V.S., Singh, H.B. and Nautiyal, C.S. (2006). Induction of plant defense enzymes and phenolics by treatment with 
plant growth - promoting rhizobacteria Serrtia marcescens NBRI1213.

Current Microbiology. 52(5): 363-368.

Legrand, M., Kauffmann, S., Pierrette, G. and Fritig, B. (1987). Biological function of pathogenesis-related proteins: Four tobacco pathogenesis-related proteins are chitinases. Proceedings of the National Academy of Sciences of the USA. 84: 67506754.

Li, L. and Steffens, J.C. (2002). Overexpression of polyphenol oxidase in transgenic tomato plants results in enhanced bacterial disease resistance. Planta. 215: 239-247.

Liang, X.Q., Holbrook, C.C., Lynch, R.E. and Guo, B.Z. (2005). $\beta-1,3-G l u c a n a s e$ Activity in Peanut (Arachis hypogaea) seed is Induced by Inoculation with Aspergillus flavus and Copurifies with a Conglutinlike Protein. Phytopathol. 95(5): 506-511.

Macdonold, M.J. and Dcunha, G.B. (2007). A Modern view of phenylalanine ammonia lyase. Biochem. Cell Biol. 85: 273282.

Mahendranathan, C., Adikaram, N.K.B. and Jayasingam, T. (2016). Enhancement of natural disease resistance of Capsicum annuиm L. against anthracnose disease through selected postharvest treatments. Proceedings of the $9^{\text {th }}$ Australasian Soil-borne Symposium, Lincoln University, New Zealand. 14-17, November, 2016.

Mauch, F., Mauch-Mani, B. and Boller, T. (1988). Antifungal hydrolases in pea tissue. II. Inhibition of fungal growth by combinations of chitinase and $\beta-1,3-$ glucanase. Plant Physiol. 88: 936-942.

Mayer, A.M. and Harel, E. (1979). Polyphenol oxidases in plants. Phytochemistry. 18(2): 193-215.
Nicholson, R.L. and Hammerschmidt, R. (1992). Phenolic compounds and their role in disease resistance. Annual Review of Phytopathology. 30: 369-389.

Passardi, F., Cosio, C., Penel, C. and Dunand, C. (2005). Peroxidases have more functions than a Swiss army knife. Plant Cell Reports. 24(5): 255-265.

Pieterse, C.M.J., Van Wees, S.C.M. and Van Pelt, J.A. (1998). A novel signaling pathway controlling induced systemic resistance in Arabidopsis. Plant cell. 10: $1571-1580$

Prasannath, K. and De Costa, D.M. (2015). Induction of peroxidase activity in tomato leaf tissues treated with two crop management systems across a temperature gradient. Proceedings of the International Conference on Dry Zone Agriculture 2015. Faculty of Agriculture, University of Jaffna, Sri Lanka. $15^{\text {th }} \& 16^{\text {th }}$ October 2015. 34-35.

Prasannath, K., De Costa, D. M. and Hemachandra, K. S. (2014). Quantification of Peroxidase activity in Chilli tissues Grown under Two Crop Protection Systems across a Temperature Gradient. Proceedings of the HETC Symposium 2014. $7^{\text {th }} \& 8^{\text {th }}$ July 2014. 102.

Prasannath, K., Dharmadasa, K.N.P., De Costa, D.M. and Hemachandra, K.S. (2014). Variations of Incidence, Types of Virus Diseases and Insect Vector Populations of Tomato (Solanum lycopersicum L.), Grown in Different Agroecological Regions of Sri Lanka under Two Crop Management Systems. Tropical Agricultural Research. 25(3): 376-395.

Punja, Z.K. and Zhang, Y-Y. (1993). Plant Chitinases and Their Roles in Resistance to Fungal Diseases. Journal of Nematology. 25(4):526-540. 
Raj, S.N., Sarosh, B.R. and Shetty, H.S. (2006). Induction and accumulation of polyphenol oxidase activities as implicated in development of resistance against pearl millet downy mildew disease. Funct Plant Biol. 33: 563-571.

Ramamoorthy, V., Raguchander, T. and Samiyappan, R. (2002). Induction of defense-related proteins in tomato roots treated with Pseudomonas fluorescens Pf1 and Fusarium oxysporum f. sp. lycopersici. Plant Soil. 239: 55-68.

Rezzonico, E., Flury, N., Meins, Jr. F. and Beffa, R. (1998). Transcriptional DownRegulation by Abscisic Acid of Pathogenesis-Related â-1,3- Glucanase Genes in Tobacco Cell Cultures. Plant Physiol. 117: 585-592.

Roy-Barman, S., Sautter, C. and Chattoo, B.B. (2006). Expression of the Lipid Transfer Protein AceAMP1 in transgenic Wheat Enhances Antifungal Activity and Defense Responses. Transgenic Res. 15(4): 435-446.

Saikia, R., Singh, B.P., Kumar, R. and Arora, D.K. (2005). Detection of Pathogenesis-related Proteins- Chitinase and $\beta-1,3-$ Glucanase in Induced Chickpea. Curr. Sci. 89(4): 659-663.

Sarvanan, T., Bhaskaran, R. and Muthuswamy, M. (2004). Pseudomonas fluorescence induced enzymological changes in banana roots (cv. Rasthali) against fusarium wilt disease. Plant Pathology Journal. 3(2): 72-70.

Sasaki, K., Iwai, T. and Hiraga, S. (2004). Ten rice peroxidases redundantly respond to multiple stresses including infection with rice blast fungus. Plant and Cell Physiology. 45(10): 1442-1452.

Seneviratne, D. M. A. S., Prasannath, K. and De Costa, D. M. (2014). Quantification of Phenylalanine Ammonia Lyase Activity in Tomato and Chilli Tissues Grown under Different Crop Management Practices and Agro-Ecological Regions in Sri Lanka. Proceedings of the $1^{\text {st }}$ Faculty of Agriculture Undergraduate Research Symposium. 23rd December 2014. p. 3.

Smart, M.G. (1991). The plant cell wall as a barrier to fungal invasion. In: The fungal spore and disease initiation in plants and animals, G.C. Cole and H.C. Hoch (eds). Plenum Press, New York. pp. 47-66.

Stevens, L.H., Davelaar, E., Kolb, R.M., Pennings, E.J.M. and Smit, N.P.M. (1998). Tyrosine and cysteine are substrates for blackspot synthesis in potato. Phytochemistry. 49: 703-707.

Thakker, J.N., Patel, N. and Kothari, I.L. (2007). Fusarium oxysporum derived Elicitor-induced changes in Enzymes of Banana leaves against wilt disease. Journal of Mycology and Plant Pathology. 37: 510513.

Thakker, J.N., Patel, S. and Dhandhukia, P.C. (2013). Induction of Defense-Related Enzymes in Banana Plants: Effect of Live and Dead Pathogenic Strain of Fusarium oxysporum $\mathrm{f}$ sp.cubense, ISRN Biotechnology, vol. 2013, 6 pages. doi:10.5402/2013/601303.

Tudzynski, B. (1997). Fungal phytohormones in pathogenic and mutualistic associations. In: The mycota, G.C. Caroll and P. Tudzynski (eds). Springer-Verlag, Berlin, Heidelberg, New York. pp. 167-184.

van Loon, L.C., Bakker, P.A. and Pieters, C.M.J. (1998). Systemic resistance induced by rhizosphere bacteria. Ann Rev of Plant Physiol. 26: 453-483.

van Loon, L.C. and Van Strien, E.A. (1999). The families of pathogenesisrelated proteins, their activities, and comparative analysis of PR-1 type proteins. Physiol. Mol. Plant Pathol. 55(2): 85-97. 
Vanitha, S.C and Niranjana, S.R. and Umesha, S. (2009). (Role of Phenylalanine Ammonia lyase and Polyphenol Oxidase in Host Resistance to Bacterial Wilt of Tomoto.) Jornal of Phytopathology. 157(9): 552-557.

Vera, P., Tornero, P. and Conejero, V. (1993). Cloning and expression analysis of a viroid-induced peroxidase from tomato plants. Molecular Plant-Microbe Interactions. 6(6): 790-794.

War, A.R., Paulraj, M.G., Ahmad, T., Buhroo, A.A., Hussain, B., Ignacimuthu, S. and Sharma, H.C. (2012). Mechanisms of Plant Defense against Insect Herbivores. Plant Signaling \& Behavior. 7(10): 13061320.

Wessels, J.G.H., Sietsma, J.H. (1981). Fungal cell walls: a survey. In: Encyclopedia of Plant Physiology, W. Tanner,
F.A. Loewus (eds). Springer Verlag, Berlin. pp. 352-394.

Whipps, J.M. (2001). Microbial interactions and biocontrol in the rhizosphere. J Exp Bot. 52: 487-511.

Wojtaszek, P. (1997). The oxidative burst: a plant's early response against infection. Biochemical Journal. 322: 681-692.

Wrobel-Kwiatkowska, M., Lorenc-Kukula, K., Starzycki, M., Oszmiañski, J., Kepczyñska, E. and Szopa, J. (2004). Expression of â-1, 3-Glucanase in Flax Causes Increased Resistance to Fungi. Physiol. Mol. Plant Pathol. 65(5): 245- 256.

Wu, C. and Bradford, K.J. (2003). Class I Chitinase and beta-1,3-Glucanase are Differentially Regulated by Wounding, Methyl Jasmonate, Ethylene and Gibberellin in Tomato Seeds and Leaves. Plant Physiol. 133: 263-273. 